体力科学 (1986) $35,111 \sim 116$

\title{
ラットの激運動後における乳酸の酸化
}

\author{
八田 秀 雄 ${ }^{*}$ 跡 見 順子** 山 本 順 子*** \\ 浅 見 俊 雄** 宮 下 充 正*
}

\section{LACTATE OXIDATION IN RATS AFTER STRENUOUS EXERCISE}

\author{
Hideo Hatta, Yoriko Atomi, Yoriko Yamamoto, \\ Toshio Asami and Mitsumasa Miyashita
}

\begin{abstract}
Oxidation of lactate at rest $(\mathrm{RE}, \mathrm{n}=4)$, or after short strenuous exercise (EX, $n=6)$ was investigated in rats. Food and water were given ad libitum before experiment. In EX, rats ran to exhaustion at the speed of $80-100 \mathrm{~m} \bullet \mathrm{min}^{-1}$. Immediately after exercise, $4 \mu \mathrm{Ci}$ of $\left[\mathrm{U}-{ }^{14} \mathrm{C}\right.$ ] lactate was injected into aorta through an indwelling catheter. In $\mathrm{RE},\left[\mathrm{U}-{ }^{14} \mathrm{C}\right]$ lactate was injected into the rats at rest. Expired gas was collected by a Brooks type bottomless chamber on treadmill belt for $120 \mathrm{~min}$. In EX, exercise duration was $109 \pm 18 \mathrm{sec}$ (mean $\pm \mathrm{SE}$ ), and maximum blood lactate concentration after the exercise was $23.7 \pm 2.1 \mathrm{mM}$ (mean $\pm \mathrm{SE}$ ). Cumulative percent recovery of ${ }^{14} \mathrm{C}$ as ${ }^{14} \mathrm{CO}_{2}$ for $120 \mathrm{~min}$ was $48.5 \pm 2.8 \%$ for $\mathrm{EX}$ and $61.7 \pm 0.9 \%$ for $\mathrm{RE}$ (mean $\pm \mathrm{SE}$ ). Significant difference was found between these two rates $(\mathrm{p}<0.01)$. After $50 \mathrm{~min}$ of recovery, mean volume of ${ }^{14} \mathrm{CO}_{2}$ expired per min in $\mathrm{RE}$ was significantly greater than that in $\mathrm{EX}(\mathrm{p}<0.01)$. Mean volume of ${ }^{14} \mathrm{CO}_{2}$ expired per min per $\dot{\mathrm{V}} \mathrm{CO}_{2}$ in $\mathrm{RE}$ was always greater than that in EX, and significant difference was found at $7.5 \mathrm{~min}$ of recovery $(\mathrm{p}<0.01)$. It is concluded that although the rate of recovery of ${ }^{14} \mathrm{C}$ as ${ }^{14} \mathrm{CO}_{2}$ after exercise is lower than that at rest, the major pathway of lactate metabolism after short strenuous exercise is oxidation.
\end{abstract}

(J. Physical Fitness Japan 1986, $35: 111 \sim 116$ )

key words : rat, strenuous exercise, lactate, oxidation, $\left[\mathrm{U}-{ }^{14} \mathrm{C}\right]$ lactate

\section{I. 研 究 目 的}

Hill および Meyerhof の研究以来 ${ }^{110)}$ ，運動中 に産生された乳酸は，回復期において $1 / 5$ が酸化 され，4/5が糖新生されるといら考えが示されて いる. 運動中に無酸素的に乳酸を産生してェネル ギーを得，回復期に乳酸を元の糖に戻すといら考 えから, 運動後の酸素摂取量は酸素負債と呼ばれ た、また筋には糖新生の律速酵素である，ホスホ エノールピルビン酸カルボキシキナーゼなどが存 在しないとされ，乳酸は肝に運ばれて糖新生され
ると考えられてきた。 しかし酸素負債は外的条件 によって変化し，必ずしも乳酸からの糖新生を表 わするのではない, といら考无提示されてい る $^{3 / 7) 18)}$. その後放射性同位元素(RI)を用いるトレ ーサー実験により，長時間運動中や筋の電気刺激 中，およびそれらの回復期において，乳酸は主と して酸化され，糖に戻される割合は高くないこと が明らかとなった ${ }^{315111141}$. また筋中でも，乳酸か らグリコーゲンを合成できることが，示されてき ている(15)17!。た乳酸の代謝には，アミノ酸の 代謝が密接に関係していることも報告されてい

* 東京大学教育学部 Faculty of Education, University of Tokyo 文京区本郷7-3-1

** 東京大学教養学部 目黒区駒場3-8-1

*** 相模女子大学

Department of Sports Sciences, College of Arts and Sciences, University of Tokyo 相模原市文京2-2-1

Sagami Woman's University 
る3).したがって運動後の乳酸の代謝には, 様々 な可能性を考虑しなければならないといえ，不明 な点が多い。

先行研究では, 絶食時や長時間運動 後のよう に，筇および肝グリコーゲン含量を低下させた状 態で，乳酸の代謝を調べる実験が行なわれてい る.グリコーゲン含量を低下させた場合，運動中 に乳酸は産生されにくく，回復期に乳酸は糖新生 されやすくなると思われる．本研究では，ラット に食慨を自由に与えた状態で, 数分で exhaustion に達する激運動を行なわせ，乳酸を多量に産生さ せた. この運動直後に, ${ }^{14} \mathrm{C}$ で標識された乳酸を 注入するトレーサー実験から，産生された乳酸の らち酸化される割合と，その時間経過を明らかに することを目的とした.

\section{II. 実 験 方 法}

ラット：日本生物材料センターより 購 入した Wistar 系ラット，雄 7 匹，倠 1 匹を用いた，実 験時の体重は, 185〜311 g であった. 実験までに， トレッドミルによる走行の練習を行なわせた．実 験前にラットに対して，アトム社製静脈用カテー テル（外径 $0.65 \mathrm{~mm}$ )を, 左頸動脈より大動脈に插 入した ${ }^{16)}$. カテーテルは背中側に回し, 頸後部中 央より出した. 実験は, ラットの体重が手術前の
値に回復した後に行なった。また実験日まで，食 飭と水は自由に与えた。

$\mathrm{RI}:\left[\mathrm{U}-{ }^{14} \mathrm{C}\right]$ 乳酸 ナトリウム (New England Nuclear，比放射能 $179.5 \mathrm{mCi} \cdot \mathrm{mmol}^{-1}$ )を, $0.9 \%$ 塩化ナトリウム溶液として用いた. 実験日ごと に, この溶液 $20 \mu \mathrm{l}$ により, 放射能を確認した.

ラットの呼気ガス採取, $\dot{\mathrm{V}} \mathrm{O}_{2}, \dot{\mathrm{V}} \mathrm{CO}_{2}$ の測定：フ クリル板を用いて，底のない $\mathrm{VO}_{2}$ 測定用チャン バー $(7.5 \times 29 \times 12 \mathrm{~cm})$ を作成し，これをトレッド ミルベルト上に乗せた $(\text { 図 } 1)^{2)}$. チャンバーの側 面と後面の下部はベルトと密着させ, 前面の下部 にはベルトとの間にわずかの㩐間を設けた. チャ ンバー内の呼気ガスは，イワキ社製ポンプにより 吸引し，アニマ製 R1500-PS 自動ガス分析器に導 いた. 自動ガス分析器は, 吸引ガス量を人間の 测定における $\dot{\mathrm{V}}_{\mathrm{E}}$ にあたるるのとして, $\mathrm{V}_{2}$, $\dot{\mathrm{V}} \mathrm{CO}_{2}, \mathrm{R}$ を算出した. トレッドミルベルトとチャ ンバー下部との間から，空気もれが生ずるかにつ いて, 窒素ガスを一定量チャンバー内に注入し， 吸引ガス中の酸素濃度の変化巾を調べる実験を行 なった. その結果, トレッドミル静止時には空気 もれは問題とならず, $40 \mathrm{~m} \cdot \mathrm{min}^{-1}$ で稼働時にも， 空気もれは $3 \%$ 以下であることを確認した。 また 呼気ガス反応の half-time は40秒である. 吸引ガ スの一部 $\left(0.51 \cdot \mathrm{min}^{-1}\right)$ を流量計で確認しながら採

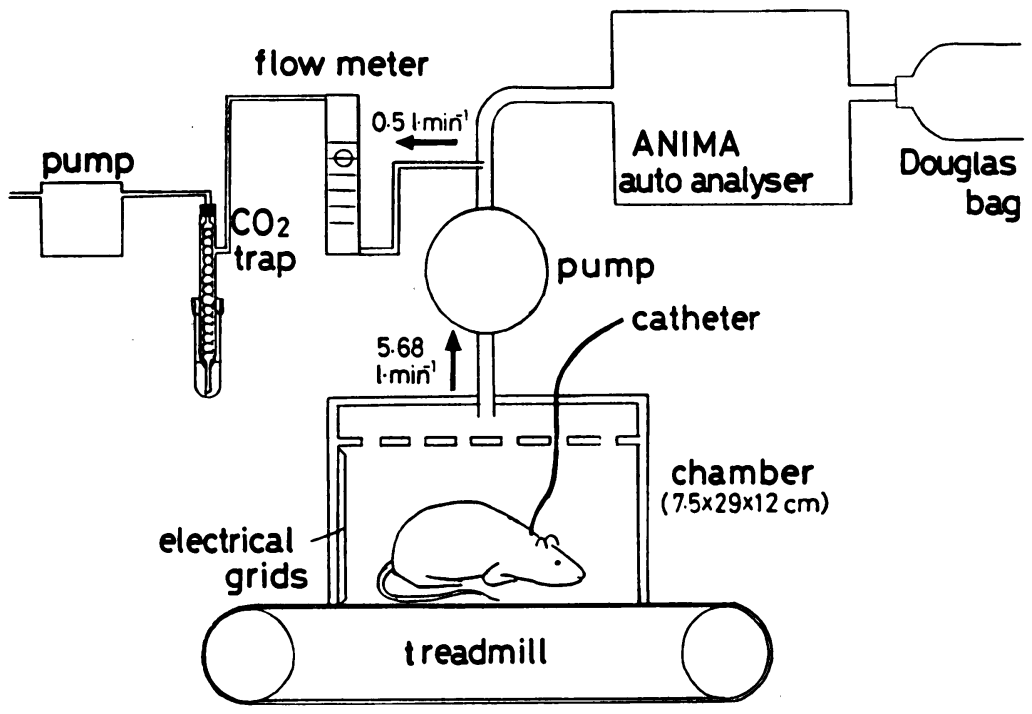

Fig. 1. Schematic diagram of the experimental apparatus. 
取し,エタノールアミン・メチルセロソルブー1: $2(\mathrm{v} / \mathrm{v})$ 液に, $\mathrm{CO}_{2}$ を吸収させ, ${ }^{14} \mathrm{CO}_{2}$ 呼出量を求 めた.

実験手順：実験は運動群 (EX, $\mathrm{n}=6)$, および安 静群(RE, $\mathrm{n}=4)$ について行なった. ます $\mathrm{RE}, \mathrm{EX}$ ともに, カテーテルより $100 \mu \mathrm{l}$ 採血し, ラット をチャンバー内に入れ，カテーテルをチャンバー 外に導いた. $\mathrm{EX}$ では $25 \mathrm{~m} \cdot \mathrm{min}^{-1}$ で 3 分間走行 し2 分間休息させた後, $80 \sim 110 \mathrm{~m} \cdot \mathrm{min}^{-1}$ の速度 で走行させ, exhaustionに至らせた. exhaustion は,ラットが電気刺激を受けても走行できない状
態とした. 運動終了後直ちに採血し, 続いて $4 \mu \mathrm{Ci}$ の $\left[\mathrm{U}-{ }^{14} \mathrm{C}\right]$ 乳酸を注入した. ラットは, 回復 120 分 まで安静を保たせた，採血は回復 $5,10,15,30$, 60，120分に行なった. ${ }^{14} \mathrm{CO}_{2}$ の捕集は，回復30分 までは 5 分ずつ，その後回復40分，60分，90分， 120分と区切って行なった. RE では運動を行なわ ず安静を保った状態で, $\left[\mathrm{U}-{ }^{14} \mathrm{C}\right\}$ 乳酸を注入した。 採血は15，30，60，120分に行なった. ${ }^{14} \mathrm{CO}_{2}$ の捕 集は $\mathrm{EX}$ と同様である. 同一ラットを $\mathrm{RE}$ とX とも行なわせる場合, 実験は最低一週間の間隔を おいて行ない，実験開始時刻も同一となるよらに

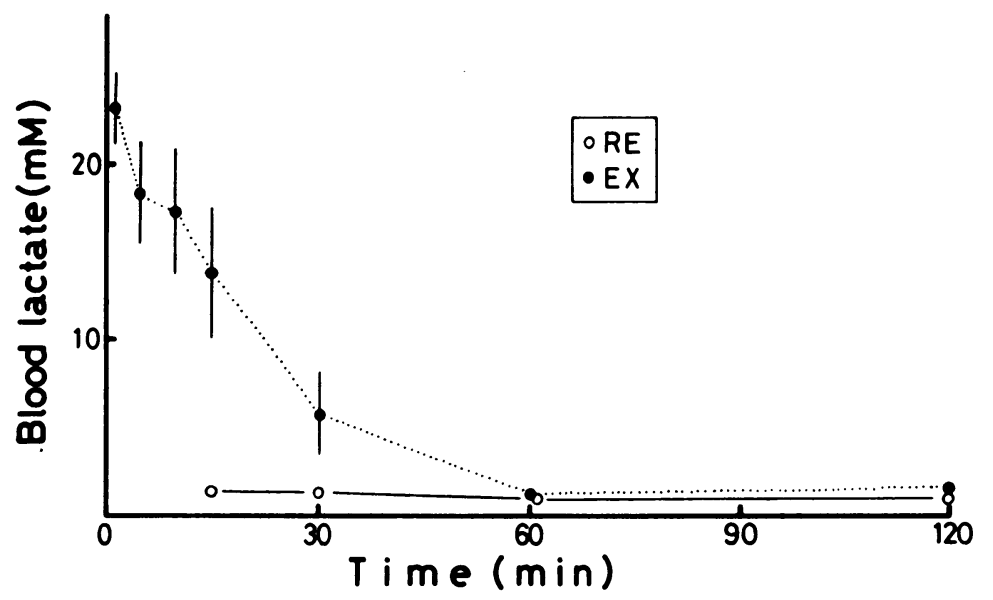

Fig. 2. Blood lactate concentrations (mean $\pm \mathrm{SE}$ ) as a function of time in $\mathrm{RE}$ and $\mathrm{EX}$.

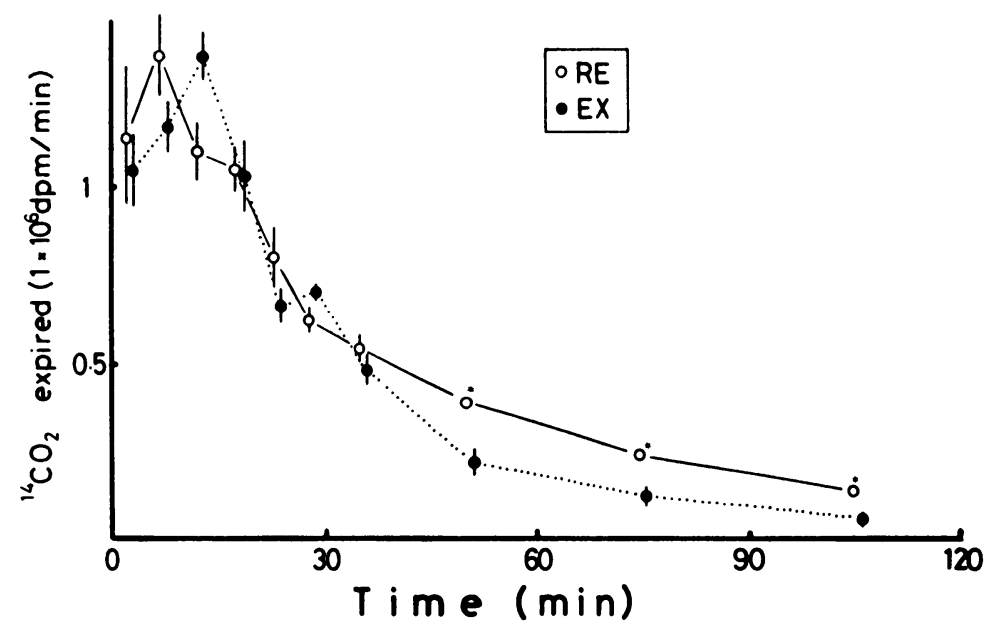

Fig. 3. Evolution of ${ }^{14} \mathrm{CO}_{2}$ following injection of $4 \mu \mathrm{Ci}$ of $\left[\mathrm{U}-{ }^{14} \mathrm{C}\right]$ lactate into aorta in rats at rest or after strenuous exercise. Points are mean $\pm S E$. *-significantly different between $\mathrm{RE}$ and $\mathrm{EX}(\mathrm{p}<0.01)$. 
した.

試料の分析方法: 採取した血液は, 直ちに氷冷 した $0.6 \mathrm{NHClO}_{4}$ により除蛋白した. 除蛋白液中 の乳酸濃度は, 酳素法により求めた ${ }^{8)} . \mathrm{CO}_{2}$ 吸収 液中の ${ }^{14} \mathrm{CO}_{2}$ の放射能は, 液体シンチレーション 法により求めた. 吸収液 $1 \mathrm{ml}$ を, $10 \mathrm{ml}$ のトルエ ンシンチレーターに溶解させ, Packard Tricarb 3255スペクトロメーターによりカウントした．計 数効率は，47〜50\%であった.

\section{III. 結果}

EX に打いて激運動の持続 時間は, $109 \pm 18$ 秒 (平均 $\pm \mathrm{SE}$ )であった. 運動後の最大血中乳酸濃度

Table 1. Cumulative percent recovery of ${ }^{14} \mathrm{C}$ as ${ }^{14} \mathrm{CO}_{2}$ for $120 \mathrm{~min}$ of recovery. ${ }^{*}$-female rat

\begin{tabular}{ccc}
\hline Rat & RE & EX \\
\hline 1 & 60.6 & 45.0 \\
$2^{*}$ & 60.0 & 43.3 \\
3 & 63.7 & \\
4 & 62.4 & \\
5 & & 39.7 \\
6 & & 55.6 \\
7 & & 51.4 \\
8 & & 55.9 \\
\hline Mean & 61.7 & 48.5 \\
SE & 0.9 & 2.8 \\
\hline
\end{tabular}

は, $23.7 \pm 2.1 \mathrm{mM}$ (平均 $\pm \mathrm{SE}$ )であった（図 2). 運 動終了から採血を行ないRI を注入するまでの時 間は，96士16秒 (平均 $\pm \mathrm{SE}$ ) であった，注入され た乳酸が酸化される反応は速く, RE, EX とも回 復 5 分までに，多くの ${ }^{14} \mathrm{CO}_{2}$ が呼出された(図 3 ). $\mathrm{RE}$ では回復7.5分において，1 分あたりの ${ }^{14} \mathrm{CO}_{2}$ 呼出量が最大となった. EX では1分あたりの ${ }^{14} \mathrm{CO}_{2}$ 呼出量は, 最大值で $\mathrm{RE}$ と同様であるすの の，時間が遅れる傾向を示した. また回復50分以 降では，1 分あたりの ${ }^{14} \mathrm{CO}_{2}$ 呼出量は, $\mathrm{RE}$ が $\mathrm{EX}$ に比して有意に大であった $(\mathbf{p}<0.01)$. EX では回 復 120 分までに，注入された放射能の平均 $48.5 \%$ が， ${ }^{14} \mathrm{CO}_{2}$ となって呼出された(表 1 ). また REで は, 注入放射能の平均 $61.7 \%$ が呼出された.この 割合は, 両群間で有意差が認められた $(\mathrm{p}<0.01)$. 1 分あたりの ${ }^{14} \mathrm{CO}_{2}$ 呼出量を, $\mathrm{VCO}_{2}$ あたりにす ると, 両群間の差が大となり, 回復7.5分では有意 差が認められた $(\mathrm{p}<0.01)$ (図 4).

\section{IV. 考察}

本研究で用いたラットの $\dot{\mathrm{V}}_{2}$ 測定装置では, トレッドミルベルトとチャンバー下部との間か ら, 空気もれが生ずるかが問題となる.そこでチ +ンバー内に窒素ガスを注入し，吸引ガス中の酸 素濃度がどれだけ低下するかにより，これを確認 した. 本研究では, トレッドミルの静止している 回復期に括いて, 呼気ガス中の ${ }^{14} \mathrm{CO}_{2}$ を測定した

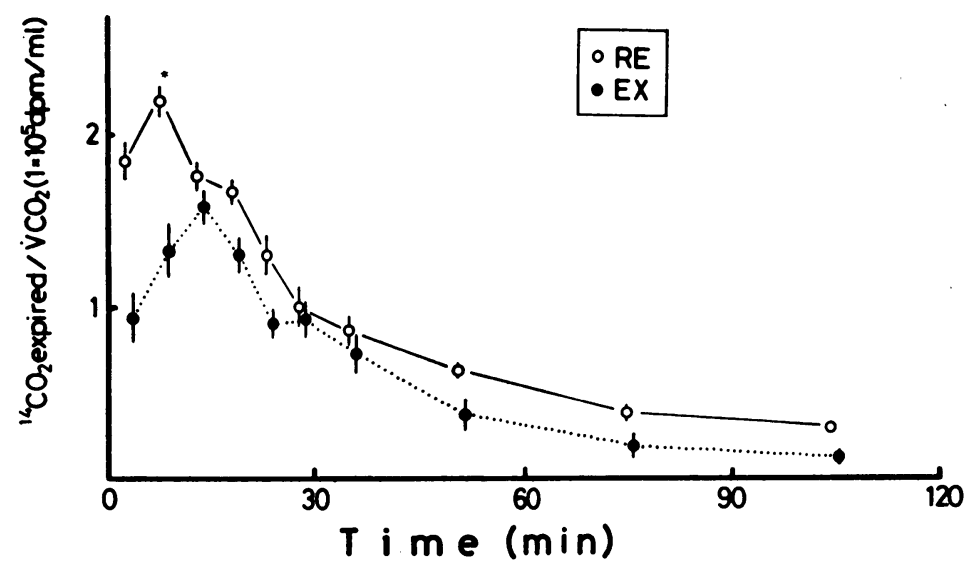

Fig. 4. Evolution of ${ }^{14} \mathrm{CO}_{2}$ per $\dot{\mathrm{V}} \mathrm{CO}_{2}$ following injection of $4 \mu \mathrm{Ci}$ of $\left[\mathrm{U}-{ }^{14} \mathrm{C}\right]$ lactate at rest or after strenuous exercise. 
ことから，空気もれは問題にならないと思われ る.また激運動中の $\dot{\mathrm{V}}_{2}$ は, 反応の half-time が40秒であり, 空気もれも考兄られ, 正確に求め ることはできなかった.この $\mathrm{VO}_{2}$ 測定用チャン バーは, 側面と後面がトレッドミルベルトと密着 しており,ラットを exhaustion に追いこみやす く, EXでは運動後に血中乳酸濃度が $20 \mathrm{mM}$ を越 え, 非常に強度の高い運動を行わせ得た. また本 研究では雌雄両ラットを用いたが, 表 1 のよう に, 雌と雄とで結果に差は認められなかった.

Brooks and Gaesser $は^{3)}$ ，長時間運動後のラッ トに, ${ }^{14} \mathrm{C}$-乳酸を腹腔投与するトレーサー実験を 行なっている.そして乳酸は主として酸化された こと，また回復 4 時間までにグリコーゲンにとり

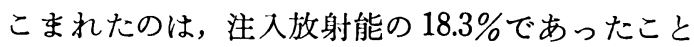
を報告した. 本研究の方法が，この報告の方法と 大きく異なる点は, 本研究では実験前に食飭を自 由とし，ラットに短時間の激運動を行なわせたこ とと，カテーテルにより RI を動脈投与したこと である，一夜の絶食と長時間運動の後では，筋お よび肝グリコーゲンは涸渴状態となり7，その場 合乳酸からのグリコーゲン合成が，克進すると思 われる. また RI の投与については血中投与が望 ましく ${ }^{12)}$ ，腹腔投与では，RIの吸収と血中への払 散に時間を要する点が，大きな問題であろう.

運動中では血中乳酸の增加とともに, 乳酸の代 謝回転率も高まるこど)，またトレーニングによ って, 運動中の乳酸除去能力が向上することが報 告されている ${ }^{6)}$. ヒトに ${ }^{14} \mathrm{C}$-乳酸や ${ }^{13} \mathrm{C}$-乳酸を注 入したトレーサー実験でも，運動中に多くの乳酸 が酸化されていることが，明らかとなった ${ }^{11141 .}$ したがって乳酸は産生されるだけでなく，一方で は代謝されて括り, 運動のエネルギーは, 乳酸の 酸化によっても得ていることがわかる. 特に酸化 能力の高いslow 線維に招いて，多く乳酸が酸化 されると推察することができよう ${ }^{15)}$. 運動後で は, 乳酸は肝に送られ $1 / 5$ が酸化され, 残りがグ リコーゲンに戻るとされた. その後, 筋内でも乳 酸からグリコーゲンが合成されることが，明らか となった ${ }^{4) 15(17)}$. しかし血中, 筋中乳酸は, 運動 後15〜30分で運動前の值に戻るが, その時点で筋,
肝グリコーゲン含量は回復しておらず, 乳酸が直 接グリコーゲンに戾されるとは考えにくいこと を, Gaesser and Brooks ${ }^{7)}$ が報告した. 本研究の 結果も, 運動中に産生された乳酸は, 回復期には 主として酸化されて除去され，グリコーゲンに戾 される割合は酸化される割合よりも，低いと思わ れることを示した，そこで回復期に打ける酸素掑 取量は，これを酸素負債として，乳酸がグリコー ゲンに戻される過程を示す，とするのみでは適切 でないといえよう、実際には多くの要素が, 運動 後の酸素摂取量に影響していると考えられる ${ }^{18)}$. ここで Hermansen and Vaage ${ }^{9)}$ は, ヒトの筋生 検から, 運動後において能中の乳酸は, 主として 㳙内でグリコーゲンに戾されると報告しており， 不明な点が多い。

安静時に比して激運動後では, 乳酸の酸化され る割合が低下する理由については，運動によって 筋グリコーゲン含量が低下し, 回復期においてグ リコーゲンが合成されていることが考えられる. 二例ずつ同一の実験条件で求めた. 腓腹筋のグリ コーゲン含量は, 運動前 $5.2,5.9$, 運動直後 1.9 , 2.1, 回復 120 分 $5.1,5.5 \mathrm{mg} \cdot \mathrm{g}_{\text {wet weight }}{ }^{-1}$ であ った．回復 120 分までに，グリコーゲンが合成さ れ，運動前の水準に戻っていることがわかる. し たがって激運動後では，乳酸は主として酸化され るものの, 安静時に比してグリコーゲンへ合成さ れる割合も高いことから, 本研究の結果が得られ たと推察できる、これには，エピネフリンが糖新 生を高めることが報告されており ${ }^{13)}$ ，運動によっ て放出された，エピネフリンの影響も考えられよ う. 回復50分以降で, $\mathrm{EX} か ゙ \mathrm{RE}$ に比して, ${ }^{14} \mathrm{CO}_{2}$ 呼出量が有意に低いことは, EX では REよりも, 乳酸の代謝回転率が高いことを示していると思わ れる、そこで乳酸は，ぞの部位でどのように代謝 されているかを求めることが, 今後の課題であ る.

\section{V. と め}

ラットを用いて, 激運動後に打ける乳酸の酸化 を調べた、食慨を自由に与えたラットに対して， 平均 109 秒で exhaustion に至る運動を行なわせ, 
運動終了直後に $4 \mu \mathrm{Ci}$ の $\left[\mathrm{U}-{ }^{14} \mathrm{C}\right]$ 乳酸を動脈注入 した. 運動後の最大血中乳酸濃度は, $23.7 \pm 2.1$ $\mathrm{mM}$ (平均 $\pm \mathrm{SE}$ )であった. 1 分あたりの ${ }^{14} \mathrm{CO}_{2}$ 呼 出量は, 安静群では回復7.5分で最大となり, 運動 群では最大值は同様であるものの, 時間が遅れる 傾向を示した. 回復 120 分までに, 注入放射能の うち, 安静群 $61.7 \pm 0.9 \%$, 運動群 $48.5 \pm 2.8 \%$ (平 均士 $\mathrm{SE}$ ) が, ${ }^{14} \mathrm{CO}_{2}$ となって呼出された. ${ }^{14} \mathrm{CO}_{2}$ 呼 出量は $\dot{\mathrm{V} C \mathrm{C}_{2}}$ あたりにすると両群間の差が大とな った.そこで激運動後には，安静時に比して酸化 される割合は低いが，乳酸は主として酸化される ことが示された.

本研究の要旨は, 第74回日本体力医学会関東地方 会において発表した。

本研究は, 東京大学アイントープ総合センターの 施設を使用して行なった. 関係各位に深く感謝しま す.

（受付 昭和60年 6 月29日）

\section{References}

1) Bendall, J. R. and Taylor, A. A. (1970): The Meyerhof quotient and the synthesis of glycogen from lactate in frog and rabbit muscle. A reinvestigation. Biochem. J., 118, 887-893.

2) Brooks, G. A. and White, T. P. (1978) : Determination of metabolic and heart rate responses of rats to treadmill exercise. J. Appl. Physiol., 45, 1009-1015.

3) Brooks, G. A. and Gaesser, G. A. (1980) : End points of lactate and glucose metabolism after exhausting exercise. J. Appl. Physiol., 49, 10571069.

4) Crabtree, B., Higgins, S. J. and Newsholme, E. A. (1972): The activities of pyruvate carboxylase, phosphoenolpyruvate carboxylase and fructose diphosphatase in muscles from vertebrates and invertebrates. Biochem. J., 130, 391-396.

5) Depocas, F., Minaire, Y. and Chatonnet, J.(1969): Rates of formation and oxidation of lactic acid in dogs at rest and during moderate exercise. Can. J. Physiol. Pharmacol., 47, 603-610.

6) Donovan, C. M. and Brooks, G. A.(1983) : Endurance training affects lactate clearance, not lac- tate production. Am. J. Physiol., 244, E83-E92.

7) Gaesser, G. A. and Brooks, G. A. (1980) : Glycogen repletion following continuous and intermittent exercise to exhaustion. J. Appl. Physiol., 49, 722-728.

8) Gutmann, I. and Wahlfeld, A. W.(1974) : L-(+)Lactate. Determination with lactate dehydrogenase and NAD. In: Methods of Enzymatic Analysis, 2 nd Ed., edited by H. U. Bergmeyer. Academic Press. New York. 1464-1468.

9) Hermansen, L. and Vaage, O. (1977) : Lactate disappearance and glycogen synthesis in human muscle after maximal exercise. Am. J. Physiol., 233, E422-E429.

10) Hill, A. V. (1914): The oxidative removal of lactic acid. J. Physiol., 48, $x$-xi.

11) Hubbard, J. L.(1973): The effect of exercise on lactate metabolism. J. Physiol., 231, 1-18.

12) Katz, J., Okajima, F., Chenoweth, M. and Dunn, A. (1981): The determination of lactate turnover in vivo with ${ }^{3} \mathrm{H}-$ and ${ }^{14} \mathrm{C}$ - labelled lactate. The significance of sites of tracer administration and sampling. Biochem. J., 194, 513-524.

13) Kusaka, M. and Ui, M.(1977) : Activation of the Cori cycle by epinephrine. Am. J. Physiol., 232, E145-E155.

14) Mazzeo, R. S., Brooks, G. A., Schoeller, D. A. and Budinger, T. F.(1982) : Pulse injection, ${ }^{13} \mathrm{C}$ tracer studies of lactate metabolism in humans during rest and two levels of exercise. Biomed. Mass. Spectro., 9, 310-314.

15) McLane, J. A. and Holloszy, J. O. (1979) : Gly. cogen synthesis from lactate in the three types of skeletal muscle. J. Biol. Chem., 254, 6548-6553.

16) Popovic, V. and Popovic, P. (1960) : Permanent cannulation of aorta and vena cava in rats and ground squirrels. J. Appl. Physiol., 15, 727-728.

17) Shiota, M., Golden, S. and Katz, J.(1984) : Lactate metabolism in the perfused rat hindlimb. Biochem. J., 222, 281-292.

18) Welch, H. G., Faulker, J. A., Barclay, J. A. and Brooks, G. A.(1970) : Ventilation response during recovery from muscular work and its relation with $\mathrm{O}_{2}$ debt. Med. Sci. Sports, 2, 15-19. 